\title{
Interactive comment on "Aerosol Vertical Mass Flux Measurements During Heavy Aerosol Pollution Episodes at a Rural Site and an Urban Site in the Beijing Area of the North China Plain" by Renmin Yuan et al.
}

\section{Renmin Yuan et al.}

rmyuan@ustc.edu.cn

Received and published: 29 June 2019

Authors reply to reviewer's comments:

Dear Anonymous Referee,

Thanks for your careful review of the manuscript. We read the reviewer's comments carefully, and have responded and taken all of the reviewer's comments into consideration and revised the manuscript accordingly. My detailed responses are as follows: 
East Asia, especially China, is facing heavy haze pollution in wintertime. Though many measurements on air pollutants have been extensively conducted across China, thereis still a lack of flux data on pollutants, which may play a substantial role in haze formation. This study combines measurements on meteorological conditions, iňćux, as well as PM2.5 concentration in BTH region to derive aerosol vertical mass iňćcux, and provide some observational insight on aerosol vertical ïňćux under stable condition. Therefore, this manuscript adds to our current knowledge of aerosol vertical exchange and its im-pact on meteorology. However,I have some concerns about the methods/data analysis used in the study and the interpretation of results, and more in-depth analysis and discussion ought to be provided. I think this manuscript can be considered for publication only if the authors could adequately address the comments below.

"Major comment: 1) There are two observation sites, a rural site (GC site) and an urban site (CAMS site). The Monin-Obukhov similarity theory (MOST) is applied in rural site because the surface is homogenous. But in the urban site, the observation was within the urban roughness sublayer (3-5 mean building height), MOST is invalid due to the lack of constant-flux conditions, the local similarity theory should be used. In other words, the function or the parameters in the similarity relationship should be different for the rural and urban site."

Response: Indeed, in the urban site (CAMS site) the observation was within the urban roughness sublayer, and the local similarity theory should be used to calculate the aerosol mass flux. But, if the local similarity theory is applied for calculation in our experiment, the local turbulence parameters and local stability parameters are required. At the CAMS site, these parameter measurements cannot be implemented due to actual conditions. So we can only choose an alternative, and used the meteorological data (temperature) measured at nearby observation points, then based on the free convection assumption (using Equation 12) the aerosol fluxes at the CAMS site were calculated. We (Yuan et al, 2015) conducted a test experiment for vertical aerosol flux in Hefei City, China, using free convection assumptions and local similarity theories to

Printer-friendly version

Discussion paper
Interactive

comment 
calculate aerosol fluxes, respectively. Comparison of the calculation results of the two methods shows that very unstable condition, $-0.15<(z-z d) / L<0$, accounts for about $62 \%$ of the time, and the relative difference is about $5 \%$. Under weak unstable and stable condition, the relative error is about $15 \%$. Although the relative error is a little large under weak unstable stable stratification conditions, the absolute difference in flux is still small. There is a weather tower in the north of Beijing. The weather tower is $6.1 \mathrm{~km}$ far from the CAMS site. The meteorological observation data from the weather tower show that the Monin-Oubhov similarity theory has a little significant error under stable condition, while the Monin-Oubhov similarity theory is still basically applicable in the case of unstable stratification (Liu et al. 2009). In the roughness sub-layers of other cities, under the condition of unstable stratification, the local similarity theory is similar to MOST (Zou et al. 2018, 2019). Urban meteorological observations show that the urban surface layer is almost always in an unstable stratification. Even if the city's upper levels are stable, it is nearly always unstable near the ground in the city (Li et al., 2007). All of this shows that our current treatment is reasonable. Please see L442-L463

Reference Li, X., Hu, F., and Shu, W.: Study on the characteristics of winter island heat islands in Beijing and the influence factors of strong and weak heat islands, Journal of the Graduate School of the Chinese Academy of Sciences, 4, 431-438, 2007. Liu Ximing, Hu Fei, Quan Lihong, Cao Xiaoyan, and Dou Junxia, 2009, Validation of the local similarity in urban boundary layer, Climatic and Environmental Research (in Chinese), 14(2): 183-191. Zou, J., Liu, G., Sun, J., Zhang, H., and Yuan, R.: The momentum flux-gradient relations derived from field measurements in the urban roughness sublayer in three cities in China, Journal Of Geophysical Research-Atmospheres, 120, 10.1002/2015jd023909, 2015. Yuan, R., Luo, T., Sun, J., Liu, H., Fu, Y., and Wang, Z.: A new method for estimating aerosol mass flux in the urban surface layer using LAS technology, Atmospheric Measurement Techniques, 9, 1925-1937, 10.5194/amt9-1925-2016, 2016. Roth, M.: Review of atmospheric turbulence over cities, Quarterly Journal of the Royal Meteorological Society, 126, 941-990, 10.1256/smsqj.56408, 
2) "The function and parameters of the similarity relationship are not universal, the authors should explain why they use these function and parameters in the paper. For example, in Eq. 4, the authors said that they take the parameters b1 and b2 follow DeBruin et al., 1995. But in DeBruin et al., 1995, it said that "For stable conditions there is no consensus on the universal function", $b 1=5, b 2=0$ were found by DeBruin et al., 1993, and "the scatter was very large". So DeBruin may not be the best choice. Especially, in Yuan et al., 2016, the parameter b1 and b2 follows Wyngaard et al., 1971., which is very different from DeBruin et al., 1993. When b1 and b2 follow DeBruin et al., 1995, it means that $\eta(\xi)$ stays constant with stability; but when b1 and b2 follow Wyngaard et al., 1971, it means that $\eta(\xi)$ changes constant with stability. The author should explain why they choose DeBruin et al., 1995."

Response: In addition to DeBruin et al., 1993 and 1995, there are a number of schemes that are used to parameterize the near-surface temperature structure parameter CT2. Available data, such as CT2, $\mathrm{u}^{*}$ and $\mathrm{T}^{*}$, were used to calculate the difference between schemes and actual data. The scheme with the smallest difference was selected. The experiment of Yuan et al (2016) was conducted over the urban surface. The scheme of DeBruin et al (1995) was used for processing of these data for unstable conditions, and the scheme of Wyngaard et al.(1971) was used for stable condition. When the free convection approximation is satisfied, the approximate expression given by Wyngaard et al., 1971 was used. The current GC site is a rural site with a flat underlying surface, where similarity theory can be applied. The parameters $T^{*}$ and $u^{*}$ were obtained from temperature-wind profiles from a tower in GC site. After comparing several parameterization schemes, we found that taking $b 1=5$ and $b 2=0$ was the best match with the actual results. So we used this scheme. Details are given below. The parameterizing scheme for the near-surface temperature structural parameter CT2 can be expressed by the formula in the literature (Wyngaard et al., 1971), i.e. 
where $z$ is the measurement height, $d$ is the zero-displacement height, $\xi=(z-d) / L$ is the nondimensional stability parameter, $L$ is the Monin-Obukhov (M-O) length and defined as. Usually, can be,

Equation $20 \geq(\mathrm{z}-\mathrm{d}) / \mathrm{L}(2)$

Equation $30 \leq(\mathrm{z}-\mathrm{d}) / \mathrm{L} \leq 2$ (3)

(See Fig.2 below for the complete formula. Eqs.(1)-(3) )

Five coefficients a1, a2, b1, b2, e1 in Eqs. (2) (3) were decided by different researchers, shown in Table 1.

Table1 Five coefficients in universal function (See Fig.4 below for Table1.)

Schemes 1, 2 and 4 were widely used, so the three were used to calculate flux for comparison in our experiment. Sensible heat flux can be calculated as,

Equation $4 \mathrm{i}=1,2,4$, for scheme number. (4)

and compared with

Equation 5 (5)

(See Fig.3 below for the complete formula. Eqs.(4)-(5) )

The variables and can be obtained from 3-D sonic anemometer or temperature-wind profiles. Comparison of sensible heat flux of Eqs. (4) and (5) is equivalent to the comparison between and in Eq. (1) Aerosol flux measurement was conducted in Hefei, China (Yuan et al. 2016), and CT2 was deduced from a LAS and L were deduced from an EC system. Taking a1=4.9, a2=9, b1=4.9, b2=2.75, and e1=0 gives the minimal difference between Eq. (4) and Eq. (5). For the experiment at the GC site, CT2 was deduced from a LAS and $L$ were deduced from wind profile and temperature profile. Comparisons of sensible heat flux between $\mathrm{Hsi}$ and $\mathrm{HsO}$ were done and shown in Fig. 1. 
(a)(b)(c) corresponding to scheme 1,2,4 respectively and statistical results are given on the lower right. (See Fig.1 below for Figure 1 )

From comparisons in Fig. 1, Scheme 4 was selected to calculate flux in the current manuscript. The effect of the footprint is not considered in our experiment. Please see Line 194-Line 200. Reference Andreas, E. L.: Estimating cn2 over snow and sea ice from meteorological data, Journal of the Optical Society of America a-Optics Image Science and Vision, 5, 481-495, 10.1364/josaa.5.000481, 1988. Wyngaard, J. C., Izumi, Y., and Collins, S. A.: Behavior of refractive-index-structure parameter near ground, J. Opt. Soc. Am., 61, 1646-1650, 10.1364/josa.61.001646, 1971. DeBruin, H. A. R., vandenHurk, B., and Kohsiek, W.: The scintillation method tested over a dry vineyard area, Boundary-Layer Meteorology, 76, 25-40, 1995. Debruin, H. A. R., Kohsiek, W., and Vandenhurk, B.: A verification of some methods to determine the fluxes of momentum, sensible heat, and water-vapor using standard-deviation and structure parameter of scalar meteorological quantities, Boundary-Layer Meteorology, 63, 231-257, 1993. Andreas, E. L.: 1989, 'Two-Wavelength Method of Measuring Path-Averaged Turbulent Surface Heat Fluxes', J. Atmos. Oceanic Tech. 6, 280-292. Maronga, B.: Monin-Obukhov Similarity Functions for the Structure Parameters of Temperature and Humidity in the Unstable Surface Layer: Results from High-Resolution Large-Eddy Simulations, Journal of the Atmospheric Sciences, 71, 716-733, 10.1175/jas-d-13-0135.1, 2014. Li, D., Bou-Zeid, E., and De Bruin, H. A. R.: Monin-Obukhov Similarity Functions for the Structure Parameters of Temperature and Humidity, Boundary-Layer Meteorology, 145, 45-67, 10.1007/s10546-011-9660-y, 2012. Hartogensis, O. K., and H. A. R. De Bruin, 2005: Monin-Obukhov similarity functions of the structure parameter of temperature and turbulent kinetic energy dissipation rate in the stable boundary layer. Bound.-Layer Meteor., 116, 253-276. Zhang, H., and Zhang, H.: Comparison of Turbulent Sensible Heat Flux Determined by Large-Aperture Scintillometer and Eddy Covariance over Urban and Suburban Ar- 
eas, Boundary-Layer Meteorology, 154, 119-136, 10.1007/s10546-014-9965-8, 2015. Braam, M., Beyrich, F., Bange, J., Platis, A., Martin, S., Maronga, B., and Moene, A. F.: On the Discrepancy in Simultaneous Observations of the Structure Parameter of Temperature Using Scintillometers and Unmanned Aircraft, Boundary-Layer Meteorology, 158, 257-283, 10.1007/s10546-015-0086-9, 2016. Lee, S.-H., Lee, J.-H., and Kim, B.Y.: Estimation of Turbulent Sensible Heat and Momentum Fluxes over a Heterogeneous Urban Area Using a Large Aperture Scintillometer, Advances In Atmospheric Sciences, 32, 1092-1105, 10.1007/s00376-015-4236-2, 2015. Thiermann, V., and Grassl, H.: The measurement of turbulent surface-layer fluxes by use of bichromatic scintillation, Boundary-Layer Meteorology, 58, 367-389, 10.1007/bf00120238, 1992. Li, X., Gao, Z., Li, Y., and Tong, B.: Comparison of Sensible Heat Fluxes Measured by a Large Aperture Scintillometer and Eddy Covariance System over a Heterogeneous Farmland in East China, Atmosphere, 8, 10.3390/atmos8060101, 2017. Yuan, R., Luo, T., Sun, J., Liu, H., Fu, Y., and Wang, Z.: A new method for estimating aerosol mass flux in the urban surface layer using LAS technology, Atmospheric Measurement Techniques, 9, 1925-1937, 10.5194/amt-9-1925-2016, 2016.

3) "In L359 The conventional meteorological parameters were measured at 20m above the ground surface. But in L275, the author said that the measurement heights of temperature and wind speed were $1.5 \mathrm{~m}$ and $10 \mathrm{~m}$ at CAMS site (Beijing). It should be clear which data were used to calculate the aerosol flux. Because the average height of the building was $24 \mathrm{~m}$ in CAMS site, and LAS was located at 43 meters. The temperature measured at $1.5 \mathrm{~m}$ within the canopy layer is different from $43 \mathrm{~m}$ above the canopy layer, and the calculation of aerosol fluxes from Eq. 12 was badly influenced."

Response: There are a few errors in depicting measurement height. The conventional meteorological parameters are measured on the same roof, 20 meters away from the receiving end and in the northwest direction of the receiving end. The measurement heights were $1.5 \mathrm{~m}$ and $10 \mathrm{~m}$ above the roof for air temperature and wind speed. Please see L336-L339.

Interactive comment
Printer-friendly version

Discussion paper 
4) "Another issue that the authors need to address is the assumption between AERI( atmospheric equivalent refractive index) and aerosol mass concentration as well as aerosol adsorption. First, there do exist some light-absorbing trace gases in the atmosphere, which may influence AERI significantly. Second, aerosol absorption generally contributes a relatively small part of the extinction. By contrast, scattering components like sulfate and organic matters dominate aerosol extinction during haze pollution episode, especially under high humidity. Last but not at least, aerosol extinction is also closely related to the number concentration and size distribution, which need to be considered here. I do not think it is technically robust to simply get the relationship between the imaginary part of the AERI and the atmospheric aerosol mass concentration in Eq.6."

Response: The light wavelength is $0.620 \mu \mathrm{m}$. This wavelength is only weakly absorbed by 03 ; therefore, the observed absorption is primarily due to aerosol (Brion et al., 1998; Lou et al., 2014; Nebuloni, 2005). Aerosol extinction is also closely related to the number concentration, size distribution, and refractive index of aerosol particles, so there is not a simple linear relationship between the imaginary part of the AERI and the atmospheric aerosol mass concentration in Eq.6. The variations in the ratio of the aerosol mass concentration to the imaginary part of the AERI will introduce errors into the aerosol mass flux measurements. RMN should be obtained by simultaneously measuring $\mathrm{Ma}$ and the imaginary part of the AERI at the same location with the LAS so that real-time RMN can be obtained. For GC site and CAMS site, measuring positions of PM10 and visibility are a little far from LAS measurement. So a constant ratio RMN is more representative than a simultaneous value. Our experiment conducted in Hefei (Yuan et al. 2016) showed that the linear correlation coefficient between PM10 and the imaginary part of the AERI is 0.94 . This indicates that constant is a reasonable assumption for a given location with a dominant aerosol type, such as urban aerosols. Of course, when measurements for aerosol flux using a LAS, PM10 and visibility are performed together, simultaneous value for RMN is better. Please see L234-L236 and L408-L422. Reference: Brion, J., Chakir, A., Charbonnier, J., Daumont, D., Parisse, 
C., and Malicet, J.: Absorption spectra measurements for the ozone molecule in the 350-830 nm region, J. Atmos. Chem., 30, 291-299, 10.1023/a:1006036924364, 1998. Lou, S., Liao, H., and Zhu, B.: Impacts of aerosols on surface-layer ozone concentrations in China through heterogeneous reactions and changes in photolysis rates, Atmos. Environ., 85, 123-138, 10.1016/j.atmosenv.2013.12.004, 2014. Nebuloni, R.: Empirical relationships between extinction coefficient and visibility in fog, Appl. Opt., 44, 3795-3804, 10.1364/ao.44.003795, 2005. Yuan, R., Luo, T., Sun, J., Liu, H., Fu, Y., and Wang, Z.: A new method for estimating aerosol mass flux in the urban surface layer using LAS technology, Atmospheric Measurement Techniques, 9, 1925-1937, 10.5194/amt-9-1925-2016, 2016.

"Minor issues: Some statements in this manuscript are very hard to follow. Language editing is needed for improving the accuracy of language as well as overall readability."

Response: We've tried our best to improve the English writing in the revised manuscript, but also a native English speaker reviewed the revised version of the manuscript.

1) "Line 43: Please rephrase 'heavy pollution weather"'

Response: heavy pollution environment Please see Line 45-46.

2) "Line 48: 'few studies' should be 'few study"'

Response: We modified it.

3) "Line 72: what is the boundary layer box model? Usually box model is zerodimensional."

Response: The boundary layer box model means the boundary layer is taken as a box. The box is filled within duration $\tau$ with flux $\mathrm{F}$, and then flux $\mathrm{F}$ can be estimated by the boundary layer box model: $\mathrm{F}=\mathrm{C}^{*} \mathrm{HBL} / \tau$ where $\mathrm{C}$ was the concentration measured at $30 \mathrm{~m}$ height, $\mathrm{HBL}$ was the measured boundary layer height averaged over the sample duration, and $\tau$ was boundary layer filling time. More details is in Ceburnis et al. (2016). 
I add an explanation. Please see Line 77-78. Referenceiijž Ceburnis, D., Rinaldi, M., Ovadnevaite, J., Martucci, G., Giulianelli, L., and O'Dowd, C. D.: Marine submicron aerosol gradients, sources and sinks, Atmospheric Chemistry and Physics, 16, 1242512439, 10.5194/acp-16-12425-2016, 2016.

4) "Line 106: should be 'makes it possible"'

Response: We modified it in Line 113.

5) "Eq. 11: replace $z$ with $(z-d)$ "

Response: We modified it. Please see Line 276.

6) "Line 304: More detail needed, not "personal experience."”

Response: We specified personal experience as "trend comparison for same variables between different heights and different locations." Please see L367-368.

7) "Line 378: weakly unstable is not free convection. The free convection assumption was not satisfied at night."

Response: When the free convection assumption is applied to weakly unstable condition at night, the assumption will result in an some uncertaintie. In many cases, similar to the LAS-derived sensible heat flux, we can only choose free convection assumption to obtain flux. Under stable conditions or weakly unstable condition, the value of the flux data is small and does not cause significant error. Of course, a better approach is to get $u^{*}$ and $T^{*}$ from meteorological variable and calculate aerosol flux according to Eq. (10). Please see L445-451.

Finally, the authors thank you for your constructive comments that help us to improve the clarity and the quality of the manuscript greatly. All the comments are answered and the modifications introduced in the revised manuscript correspondingly. We sincerely hope our answers can relieve doubts and give a better description of our work. 
Please also note the supplement to this comment:

ACPD

https://www.atmos-chem-phys-discuss.net/acp-2018-1265/acp-2018-1265-AC2-

supplement.pdf

Interactive comment on Atmos. Chem. Phys. Discuss., https://doi.org/10.5194/acp-2018-1265,

Interactive 2019.

comment 
ACPD
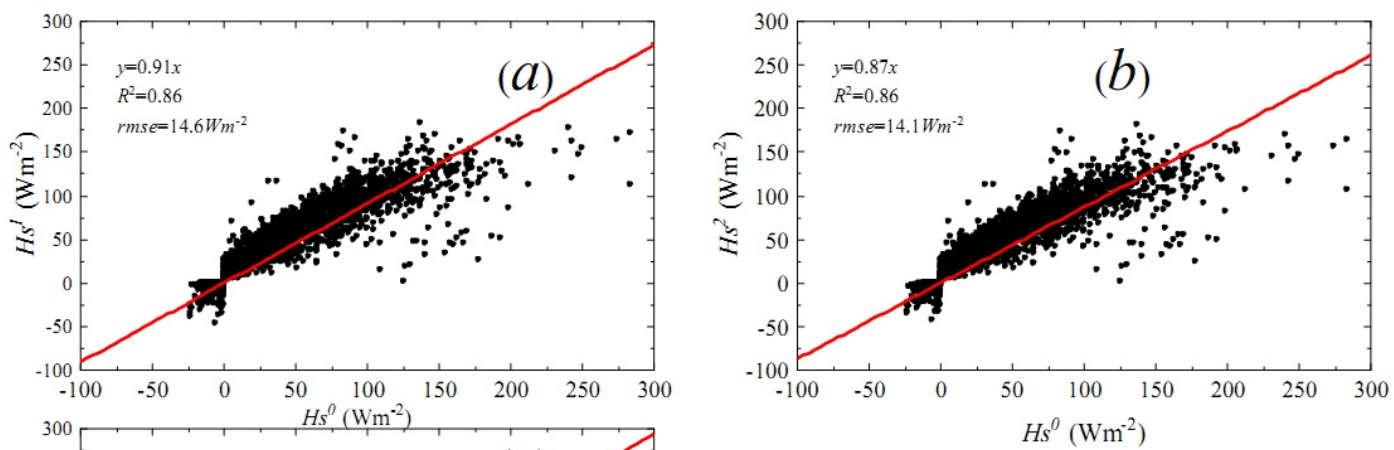

Interactive

comment

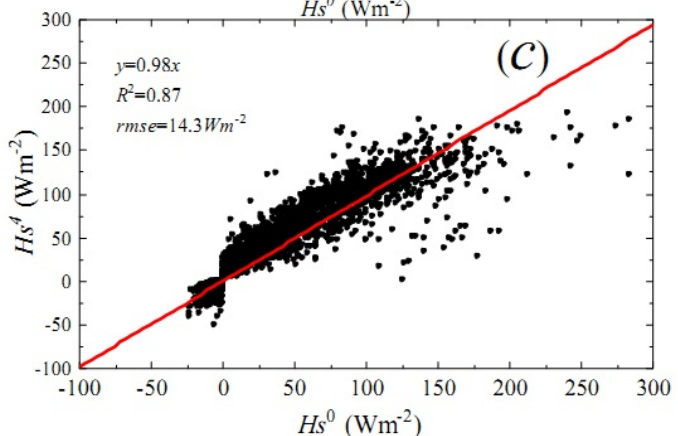

statistical results

\begin{tabular}{|l|l|l|l|}
\hline No & Slope & $\mathrm{R}^{2}$ & $\mathrm{RMSE}\left(\mathrm{Wm}^{-2}\right)$ \\
\hline 1 & 0.91 & 0.86 & 14.6 \\
\hline 2 & 0.87 & 0.86 & 14.1 \\
\hline 4 & 0.98 & 0.87 & 14.3 \\
\hline
\end{tabular}

Fig. 1. Figure 1 


$$
\frac{C_{T}^{2}(z-d)^{2 / 3}}{T_{*}^{2}}=\eta\left(\frac{z-d}{L}\right)
$$

where $\mathrm{z}$ is the measurement height, $\mathrm{d}$ is the zero-displacement height, $\xi=(\mathrm{z}-\mathrm{d}) / \mathrm{L}$ is the nondimensional stability parameter, $\mathrm{L}$ is the Monin-Obukhov (M-O) length and defined

as $L=\frac{\bar{T} u_{*}^{2}}{\kappa g T_{*}}$. Usually, $\eta\left(\frac{z-d}{L}\right)$ can be,

$$
\begin{gathered}
\eta\left(\frac{z-d}{L}\right)=a_{1}\left[1-a_{2} \frac{z-d}{L}\right]^{-2 / 3} \quad 0 \geq(\mathrm{z}-\mathrm{d}) / \mathrm{L} \\
\eta\left(\frac{z-d}{L}\right)=b_{1}\left[1+b_{2}\left(\frac{z-d}{L}\right)^{e_{1}}\right] \quad 0 \leq(\mathrm{z}-\mathrm{d}) / \mathrm{L} \leq 2
\end{gathered}
$$

Fig. 2. Equations 1-3 
Schemes 1, 2 and 4 were widely used, so the three were used to calculate flux for comparison in our experiment. Sensible heat flux can be calculated as,

$$
H_{S}{ }^{i}=C_{p} \rho u_{*} \sqrt{\frac{C_{T}^{2} z^{2 / 3}}{\eta(z / L)}} \mathrm{i}=1,2,4 \text {, for scheme number. }
$$

and compared with

$$
H_{S}^{0}=C_{p} \rho u_{*} T_{*}
$$

The variables $u_{*}$ and $T_{*}$ can be obtained from 3-D sonic anemometer or temperature-wind profiles. Comparison of sensible heat flux of Eqs. (4) and (5) is equivalent to the comparison between $\sqrt{\frac{C_{T}^{2} z^{2 / 3}}{\eta(z / L)}}$ and $T_{*}$ in Eq. (1)

Fig. 3. Equations 4-5 
Table1 Five coefficients in universal function

\begin{tabular}{|l|l|l|l|l|l|l|}
\hline $\begin{array}{l}\text { Scheme } \\
\text { no }\end{array}$ & $\mathrm{a}_{1}$ & $\mathrm{a}_{2}$ & $\mathrm{~b}_{1}$ & $\mathrm{~b}_{2}$ & $\mathrm{e}_{1}$ & References \\
\hline $\mathbf{1}$ & $\mathbf{4 . 9}$ & $\mathbf{7}$ & $\mathbf{4 . 9}$ & $\mathbf{2 . 7 5}$ & $\mathbf{1}$ & Wyngaard,1971; He_2018 \\
\hline $\mathbf{2}$ & $\mathbf{4 . 9}$ & $\mathbf{6 . 1}$ & $\mathbf{4 . 9}$ & $\mathbf{2 . 2}$ & $\mathbf{2 / 3}$ & $\begin{array}{l}\text { Andreas(1988,1989),Zhang(2015), } \\
\text { Braam_2016,Lee_2015, Li,2017 }\end{array}$ \\
\hline 3 & 4.9 & 7 & 6.34 & 7 & 1 & Thierrnann 等 1992 \\
\hline $\mathbf{4}$ & $\mathbf{4 . 9}$ & $\mathbf{9}$ & $\mathbf{5}$ & $\mathbf{0}$ & $\mathbf{1}$ & De Bruin 等, 1993,1995 \\
\hline 5 & - & - & 4.9 & 2.4 & $2 / 3$ & Hartogensis 等, 2005 \\
\hline 6 & 6.1 & 7.6 & & & & Maronga_2014 \\
\hline 7 & 6.7 & 14.9 & 4.5 & 1.3 & $2 / 3$ & Li et al.,2012 \\
\hline 8 & & & 4.7 & 1.6 & $2 / 3$ & Hartogensis,2005 \\
\hline
\end{tabular}

Interactive

comment

Fig. 4. Table1 